\title{
Melatonin Pre-treatment Alleviates UVA Radiation Induced Oxidative Stress and Apoptosis in the Skin of a Diurnal Tropical Rodent Funambulus pennanti
}

\author{
Soumik Goswami and Chandana Haldar
}

Pineal Research Lab, Department of Zoology, Banaras Hindu University, Varanasi, 221005, Uttar Pradesh, India

*Corresponding Author: Chandana Haldar, Pineal Research Lab, Department of Zoology, Banaras Hindu University, Varanasi 221005, Uttar Pradesh, India, Tel: 91-8052222271, +91-9415222261; E-mail: chaldar2001@yahoo.com

Received date: June 04, 2016; Accepted date: October 24, 2016; Published date: November 04, 2016

Copyright: @ 2016 Goswami S. This is an open-access article distributed under the terms of the Creative Commons Attribution License, which permits unrestricted use, distribution, and reproduction in any medium, provided the original author and source are credited.

\begin{abstract}
UV radiation has been established as a pro-oxidant that mediates tissue injury by triggering the generation of free radicals. However UVA induced oxidative injury has never been investigated before in the skin of a tropical diurnal rodent which spends longer time directly under the sun for foraging. The present study aimed to note the level of oxidative stress induced by $6.36 \mathrm{Jcm}^{-2}$ UVA radiations on the skin and its possible prevention by melatonin. The oxidative load was assessed by the activities of key antioxidant enzymes (superoxide dismutase (SOD), glutathione peroxidase (GSH-Px) and catalase (CAT)) and generation of thiobarbituric acid reactive substances (TBARS). Cutaneous apoptosis if any was checked by the expression of Bcl-2, p53 and Heme oxygenase-I (HO-I). Melatonin membrane receptor expression (MT1) and AANAT activity was also investigated to elucidate the protective effect of melatonin. UVA radiation increased the lipid peroxidation, suppressed the enzymatic antioxidant defense system and increased the HO-I expression. Melatonin restored redox balance and up regulated Bcl-2 and down regulated p53 levels. The restoration of AANAT activity also proved beneficial. In summary melatonin can be a part of topical applications or oral supplements that might help to reduce the UVA radiation mediated cutaneous oxidative damages.
\end{abstract}

Keywords UVA; Apoptosis; Oxidative load; Heme oxygenase-I; Melatonin

\section{Introduction}

Skin is the largest organ of the body and is an interface between the body and external biotic and abiotic factors. UV radiation has gained importance in the scientific community ever since the depletion of the stratospheric ozone has come to knowledge. UV radiation has a variety of impact on skin and one of them is acute inflammation [1]. The incidences of skin anomalies have increased due to the excessive recreational exposure to solar UV radiation and also due to the purposeful tanning by UVA (ultraviolet type A) tubes in salons $[2,3]$. The UVA radiations can completely penetrate the ozone layer and reaches deep into the dermal region of the skin [4]. The physiological damages incurred by UVR are wavelength specific and hence is different in case of UVA and UVB radiations $[5,6]$. It has been well established that UVR induces inflammation, immune-suppression and mutations in the skin that gets transformed into malignancies [7]. The primary damage associated with UVA radiation is the oxidative stress mediated tissue damage $[8,9]$. The toxic and highly reactive free radicals like the superoxide radicals $\left(\mathrm{O}_{2}^{-}\right)$react with lipids, protein and DNA and causes untimely cell death [10]. However the dose of UVA is very crucial as only at particular doses it initiates the oxidative stress generation. Therefore, keeping in mind all the information on UVA mediated oxidative injuries; we checked the oxidative potential of UVA at a particular dose in the skin of a tropical rodent Funambulus pennanti. The geographical location of a place is very important in respect to the amount of UVR it receives and the equatorial regions get the maximum UVR. Funambulus pennanti being a tropical diurnal rodent, its foraging activity is mostly during the daytime and hence it gets exposed to solar UVR maximally, a condition that can be compared with the excessive outdoor activities as in case of humans and hence is an appropriate model for the study. We investigated the UVA induced oxidative stress in the skin of the rodent in terms of lipid peroxidation which is primarily affected by free radicals and higher lipid peroxidation does actively lead to apoptosis $[11,12]$. However, we tested the effects of a well-known antioxidant melatonin as pretreatment to counteract the oxidative damages caused by UVA. To establish the oxidative damages of the skin and whether the melatonin pre-treatment is effective, we checked the expression pattern of apoptosis markers like Bcl-2, p53 and the stress protein Heme oxygenase I (HO-I) in order to propose the possible mode of action of melatonin that is involved in the alleviation of UVA mediated oxidative damages, to make the study a first of its kind that investigates the UVA mediated oxidative stress in the skin of a tropical rodent and its possible alleviation by a pre-treatment of melatonin.

\section{Materials and Methods}

\section{Non ionizing ultraviolet radiation A (UVA)}

The UVA (Philips India Pvt. Ltd.) lamps which emit light only in the UVA range of $320 \mathrm{~nm}$ to $380 \mathrm{~nm}$ were used to deliver a dose of 6.36 $\mathrm{Jcm}^{-2}$ for $30 \mathrm{~min} /$ day on the shaved abdominal skin $\left(12 \mathrm{~cm}^{2}\right)$, having a skin (shaved) to UVA distance of $30 \mathrm{~cm}$, for 4 days in a specially designed UV chamber. The specificity of the UV tube to emit UV only in the UVA wavelength was verified from the photometric data provided by the company. The dose selection was based on various earlier studies on UVA induced oxidative damages [13,14]. Hussein et al. [15] suggested that $6 \mathrm{Jcm}^{-2}$ is the minimum dose that can induce oxidative stress and suppress antioxidant defenses in the skin. Hence, a similar dose was used for the present study in case of the present study as well. 


\section{Chemicals and treatments}

All the chemicals, drugs and hormones such as melatonin were purchased from Sigma-Aldrich Chemicals, St. Louis, Missouri, USA. Melatonin stock was prepared freshly by dissolving in trace amounts of absolute ethanol $(10 \mu \mathrm{l})$ and then diluting in $0.9 \%$ normal saline to the desired concentration. It was stored at $4^{\circ} \mathrm{C}$ in amber coloured glass bottle to avoid photo-degradation.

\section{Study design}

All the experiments on animals were conducted in accordance with Institutional Practice and within the framework of the Revised Animals Act (Scientific Procedures) of 2002 of the Government of India on Animal Welfare. A total of twenty male squirrels weighing 100 $\mathrm{g} \pm 10 \mathrm{~g}$ and of 10 months of age (as determined by cranium diameter, incisor length) [16] were maintained in photoperiodic conditions of 12L:12D (lights on from 06:00 $\mathrm{h}$ to $18: 00 \mathrm{~h}$ ) equivalent to ambient conditions for the autumn months of August to October and food and water was provided ad libitum. The squirrels were divided into four groups ( $\mathrm{N}=5$ for each group) consisting of Group A- control saline treated only, Group B- $6.36 \mathrm{~J} \mathrm{~cm}^{-2}$ UVA (30 min for 4 days), Group C$100 \mu \mathrm{g} / 100 \mathrm{~g}$ body weight melatonin treated and Group D- $100 \mu \mathrm{g} / 100$ g body weight melatonin pre-treated plus $6.36 \mathrm{Jcm}^{-2}$ UVA irradiated. The abdominal area $\left(12 \mathrm{~cm}^{2}\right)$ of all the squirrels was shaved and cleaned with $70 \%$ alcohol before irradiating with UVA. Group A and B squirrels were shaved in the same abdominal area but not irradiated. The melatonin treatment in both Group $\mathrm{C}$ as well as D was continued for the same time period as UV radiation i.e. 4 days. Melatonin injections were given subcutaneously (s.c.) under dim red light during evening hours hour before the lights turned off (6:00 am to $6: 30 \mathrm{pm}$ lights on). All the squirrels were sacrificed under deep ether anaesthesia. A small portion of UVA exposed shaved abdominal skin was dissected out on ice, cleaned and then processed for biochemical estimations to determine activities of the antioxidant enzymes and western blotting.

\section{Lipid peroxidation assay by TBARS level estimation}

Skins were excised and weighed for the preparation of $10 \%$ tissue homogenates in $20 \mathrm{mM}$ Tris Hydrochloride (Tris-HCl) buffer ( $\mathrm{pH} 7.4$ ). The homogenates were centrifuged at $3000 \mathrm{x} \mathrm{g}$ for $15 \mathrm{~min}$ at $4^{\circ} \mathrm{C}$ and supernatant was subjected to thiobarbituric acid (TBA) assay as described by Ohkawa et al. [17]. The supernatant was mixed with 2.8 $\mathrm{mM}$ butylated hydroxy toluene (BHT), 8.1\% SDS, 20\% Glacial Acetic acid and $0.8 \%$ Thiobarbituric acid (TBA) and boiled for $1 \mathrm{~h}$ at $100^{\circ} \mathrm{C}$ The reaction was immediately cooled in running water and vigorously shaken with n-butanol:pyridine (15:1). The mixture was centrifuged at $1500 \mathrm{x} \mathrm{g}$ for $10 \mathrm{~min}$ and the absorbance of the upper phase was checked at $534 \mathrm{~nm}$.

\section{Superoxide dismutase assay}

Ten percent homogenates of skin tissues were processed for SOD activity assay as per the mentioned protocol of Das et al. [18]. Hundred microliter of enzyme extract was mixed in a $1.4 \mathrm{ml}$ reaction mixture containing $20 \mathrm{mM}$ L-Methionine, $1 \%$ (v/v) Triton X, $10 \mathrm{mM}$ Hydroxylamine hydrochloride and $50 \mathrm{mM}$ EDTA. $80 \mu \mathrm{l}$ of $50 \mu \mathrm{M}$ Riboflavin was then added and the whole mixture was incubated under $20 \mathrm{~W}$ white light for $10 \mathrm{~min}$. The reaction was stopped by adding freshly prepared Greiss reagent and the OD was taken at $543 \mathrm{~nm}$.

\section{Indirect Catalase Activity assay}

Ten percent homogenates of skin tissues was processed for the assay in a reaction mixture comprising $0.8 \mathrm{mM} \mathrm{H}_{2} \mathrm{O}_{2}, \mathrm{PBS}$ and potassium dichromate in glacial acetic acid. The reaction was stopped by heating in a water bath for $10 \mathrm{~min}$ and the OD was taken at $570 \mathrm{~nm}$ and the decrease in $\mathrm{H}_{2} \mathrm{O}_{2}$ content was calculated. The depletion of $\mathrm{H}_{2} \mathrm{O}_{2}$ by catalase present in skin homogenate was depicted as catalase activity. The standard curve was calibrated with varying concentrations of 0.2 $\mathrm{mM} \mathrm{H}_{2} \mathrm{O}_{2}$ in PBS [19].

\section{Glutathione peroxidase assay}

Tissue homogenates were processed for protein estimation and 150 $\mu \mathrm{g}$ of protein was mixed in a reaction mixture comprising $50 \mathrm{mM}$ phosphate buffer $\mathrm{pH} 7,1 \mathrm{mM}$ EDTA, $1 \mathrm{mM}$ sodium azide, $0.5 \mathrm{mM}$ $\mathrm{NADPH}$, and $0.2 \mathrm{mM}$ reduced glutathione $(\mathrm{GSH})$ and 1 unit of glutathione reductase. The reaction was allowed to equilibrate for 1 min at room temperature. The reaction was initiated by addition of 0.1 $\mathrm{mM} \mathrm{H}_{2} \mathrm{O}_{2}$ and the decrease in the OD was recorded at $340 \mathrm{~nm}$ for 3 $\mathrm{min}$ at every $30 \mathrm{sec}$ interval. The glutathione peroxidise activity was calculated as nmoles of NADPH oxidised $/ \mathrm{min} / \mathrm{mg}$ protein according to Mantha et al. [20].

\section{AANAT activity assay}

Tissues were dissected out and quickly frozen in liquid nitrogen. Homogenates were prepared by sonication in $0.2 \mathrm{M}$ phosphate buffer $\mathrm{pH}$ 7.4. $10 \mu \mathrm{l}$ of homogenates were mixed in a reaction mixture containing $6 \mathrm{~mm}$ tryptamine hydrochloride, $0.5 \mathrm{mM}$ Acetyl-coA and $3 \mathrm{H}$ Acetyl-coA $(0.2 \mu \mathrm{Ci} /$ assay). The reaction mixture was incubated at $37^{\circ} \mathrm{C}$ for $20 \mathrm{~min}$ and then the reaction was stopped by addition of 180 $\mu$ l $0.2 \mathrm{M}$ phosphate buffer. The mixtures were then transferred to scintillation vials containing $3 \mathrm{ml}$ of scintillation fluid (PPO and POPOP in toluene). After 24 hours of incubation at room temperature in dark the radioactivity was recorded in a beta scintillation counter. The activity of the enzyme was expressed as nmoles of $\mathrm{N}$-acetyl tryptamine formed/min/gm tissue weight according to Chae et al. [21]. Western blot analysis for MT1-R, Bcl-2, HO-I and p53 expression in whole skin lysates Western blot analysis was performed following the method of Goswami and Haldar [22].

Tissues were dissected out and lysed in RIPA buffer (1\% (v/v) Igel CA-630, 0.5\% (w/v) sodium deoxycholate, $0.1 \%(\mathrm{w} / \mathrm{v})$ sodium dodecyl sulfate (SDS) in phosphate-buffered solution (PBS) containing aprotonin and sodium orthovanadate). Aliquots containing $100 \mu \mathrm{g}$ protein were resolved by $12 \% \quad(\mathrm{w} / \mathrm{v})$ SDS-polyacrylamide gel electrophoresis for MT1-R, Bcl-2, HO-I and 10\% (w/v) gel for p53, followed by electro-transfer onto a nitrocellulose membrane (ThermoScientific, Waltham, USA) membrane. The membranes were blocked in a blocking buffer containing 5\% non-fat dried milk in PBST for 60 min. Immuno-detection was carried out using melatonin receptor MT1, Bcl-2, p53 (Santa Cruz Biotechnology Inc., Texas, USA, diluted 1:500) and HO-I (Thermo-Scientific, Waltham, USA, diluted 1:250) antibodies followed by horseradish peroxidase conjugated secondary antibody (Santa Cruz Biotechnology Inc., Texas, USA diluted 1:1000, Donkey Anti-goat and Goat Anti-rabbit), which was detected using chemiluminescence (ECL) system (Merc, Millipore, USA). The detected film was quantified for optical density using Scion Image analysis software. The ratio of density was calculated with control $\beta$ actin (Sigma-Aldrich Chemicals, St. Louis, Missouri, USA) expression and expressed as \% control value. 
Citation: Gowsami S, Haldar C (2016) Melatonin Pre-treatment Alleviates UVA Radiation Induced Oxidative Stress and Apoptosis in the Skin of a Diurnal Tropical Rodent Funambulus pennanti. J Nucl Med Radiat Ther 8: 318. doi:10.4172/2155-9619.1000318

Page 3 of 7

\section{Statistical analysis}

All the data were expressed as mean \pm SEM. The statistical analysis was performed with one-way analysis of variance (ANOVA) followed by Tukey's HSD multiple range tests. The differences were considered significant when $\mathrm{p}$ value was at $5 \%$ and $1 \%(\mathrm{p}<0.01, \mathrm{p}<0.05)$.

\section{Results}

\section{Oxidative stress of the skin following UVA radiation}

The lipid peroxidation as depicted by the TBARS assay (Figure 1) indicated significantly high values in case of the UVA treatment (Group B) when compared with the control (Group A). Melatonin treatment (Group C) decreased the TBARS levels significantly $(p<0.001)$ when compared with the control animals of Group A. Similarly the melatonin pre-treatment (Group D) caused a decline in the TBARS level significantly $(\mathrm{p}<0.001)$ when compared with the UVA treated group (Group B).

The activity of the enzyme CAT decreased significantly $(\mathrm{p}<0.01)$ in the UVA treated squirrels of Group B (Figure 2). However, the CAT activity showed no significant change following melatonin administration in Group C squirrels. Melatonin pre-treatment to the squirrels of Group D also had no significant difference in the CAT enzyme activity when compared with the UVA treated group (Group $B)$. The activity of SOD significantly increased (Figure 3 ) following melatonin treatment (Group $\mathrm{C})(\mathrm{p}<0.01)$ and declined in the UVA treated Group B squirrels when compared with the control (Group A) squirrels.

Likewise, the Group D squirrels showed a significant increase $(\mathrm{p}<0.001)$ in the activity of the SOD when compared with the UVA treated group (Group B) but was lower than control and melatonin treated groups. The GSH-Px activity (Figure 4 ) increased significantly in the melatonin treated group (Group C) while the enzyme activity declined significantly in case of the UVA irradiated squirrels (Group B).

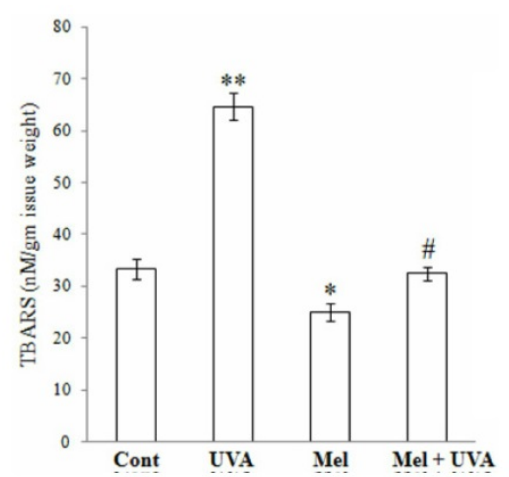

All the data were analyzed by one-way ANOVA followed by Tukey's HSD test. Bars represent Mean + SEM

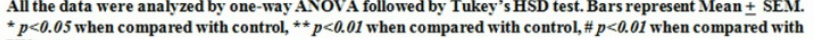
$* p<0.05$ wh
UV group

Figure 1: Effect of melatonin pre-treatment $(100 \mu \mathrm{g} / 100 \mathrm{~g}$ b. wt.) on TBARS level in skin of Funambulus pennanti following in vivo exposure of $6.36 \mathrm{~J} / \mathrm{cm}^{2}$ UVA radiation.

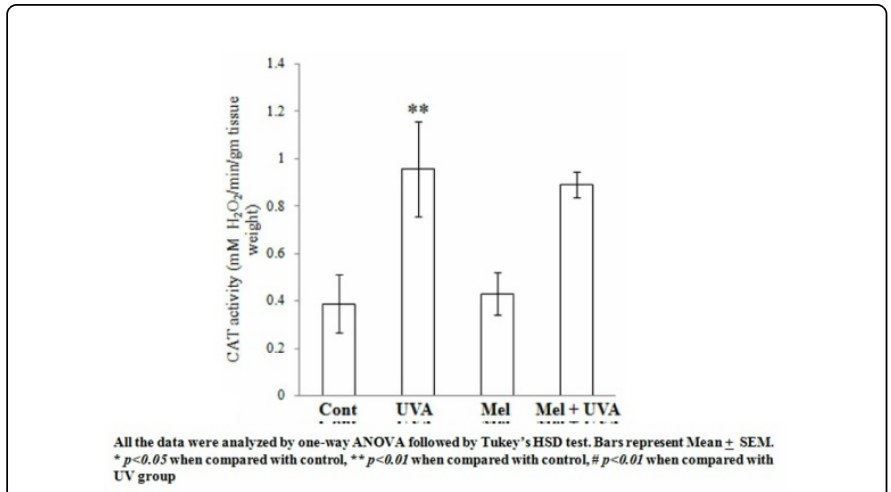

Figure 2: Effect of melatonin pre-treatment $(100 \mu \mathrm{g} / 100 \mathrm{~g}$ b. wt.) on $\mathrm{H}_{2} \mathrm{O}_{2}$ depletion (catalase activity) in the skin of Funambulus pennanti following in vivo exposure of $6.36 \mathrm{~J} / \mathrm{cm}^{2}$ UVA radiation.

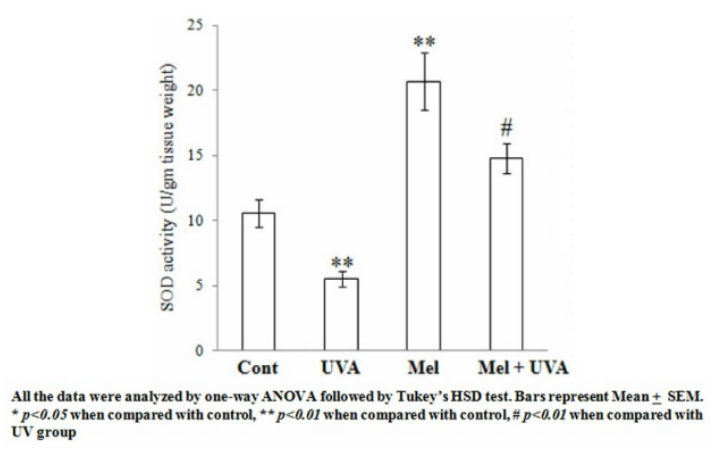

Figure 3: Effect of melatonin pre-treatment $(100 \mu \mathrm{g} / 100 \mathrm{~g} \mathrm{~b}$. wt.) on SOD activity in skin of Funambulus pennanti following in vivo exposure of $6.36 \mathrm{~J} / \mathrm{cm}^{2} \mathrm{UVA}$ radiation.

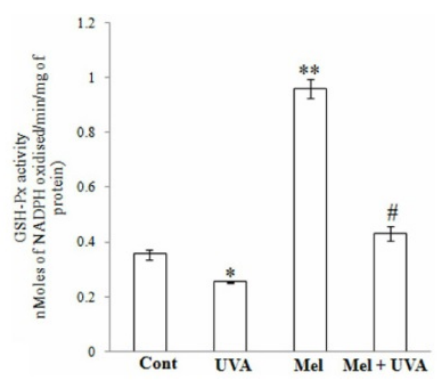

All the data were analyzed by one-way ANOVA followed by Tukey's HSD test. Bars represent Mean \pm SEN $* p<0.05$ when compared with control, $* * p<0.01$ when compared with control, $\# p<0.01$ when compared with
UV group

Figure 4: Effect of melatonin pre-treatment $(100 \mu \mathrm{g} / 100 \mathrm{~g}$ b. wt.) on glutathione peroxidase activity of skin of Funambulus pennanti following in vivo exposure of $6.36 \mathrm{~J} / \mathrm{cm}^{2}$ UVA radiation.

However in case of the squirrels pre-treated with melatonin before the UVA radiation (Group D), the GSH-Px activity got augmented when compared with the UVA treated squirrels of Group B. 
Citation: Gowsami S, Haldar C (2016) Melatonin Pre-treatment Alleviates UVA Radiation Induced Oxidative Stress and Apoptosis in the Skin of a Diurnal Tropical Rodent Funambulus pennanti. J Nucl Med Radiat Ther 8: 318. doi:10.4172/2155-9619.1000318

Page 4 of 7

\section{AANAT activity, melatonin membrane receptor MT1, Bcl-2, p53 and HO-I expression in whole skin lysates}

The AANAT activity (Figure 5) was significantly increased $(\mathrm{p}<0.01)$ in the melatonin treated squirrels (Group C) when compared with the control Group A. However the UVA radiation (Group B) caused a significant decrease in the enzyme activity than the Group A animals, while melatonin pre-treatment to the Group D animals partly recovered the enzyme activity when compared with the UVA treated group $(\mathrm{p}<0.01)$.

The MT1 receptor expression (Figure 6) was significantly up regulated $(\mathrm{p}<0.01)$ in both UVA (Group B) as well as melatonin treated squirrels (Group C) when compared to the control squirrels (Group A). On the contrary the melatonin administration before UVA radiation (Group D) caused a significant down regulation of the MT1expression when compared with the UVA treated group $(\mathrm{p}<0.01)$. The Bcl-2 expression (Figure 7) depicted a significant increase following melatonin treatment (Group $\mathrm{C}$ ) and the UVA irradiation (Group B) caused a significant decline in the expression pattern.

However, the melatonin pre-treatment (Group D) before the UVA radiation significantly restored the expression of $\mathrm{Bcl}-2$ when compared with Group B squirrels ( $<<0.01$ ). The expression of p53 (Figure 8) was up regulated by UVA in the skin of Group B squirrels. However, melatonin pre-treatment (Group D) significantly lowered the expression of p53 when compared with the UVA irradiated squirrels (Group B).

The Heme oxygenase I (HO-I) expression (Figure 9) was significantly up regulated by UVA irradiation (Group B) when compared with the control but was almost similar to control in case of melatonin treated Group C animals. The Group D squirrels which received melatonin treatment prior to UVA depicted significantly lowered expression of HO-I when compared with the UVA irradiated squirrels of Group B.

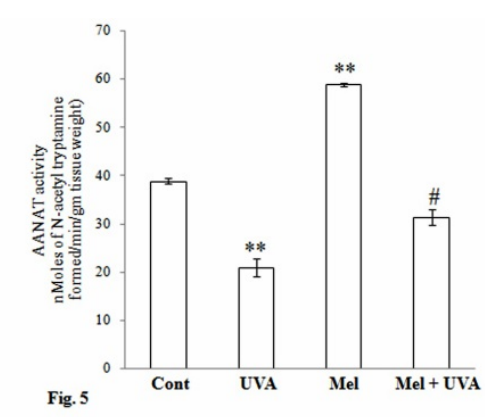

All the data were analyzed by one-way ANOVA followed by Tukey's HSD test. Bars represent Mean + SEML ${ }_{* \star}^{*} p<0.01$ when compared with control, $\# p<0.01$ when compared with $\mathrm{UV}$ group

Figure 5: Effect of melatonin pre-treatment ( $100 \mu \mathrm{g} / 100 \mathrm{~g}$ b. wt.) on AANAT activity of skin of Funambulus pennanti following in vivo exposure of $6.36 \mathrm{~J} / \mathrm{cm}^{2} \mathrm{UVA}$ radiation.

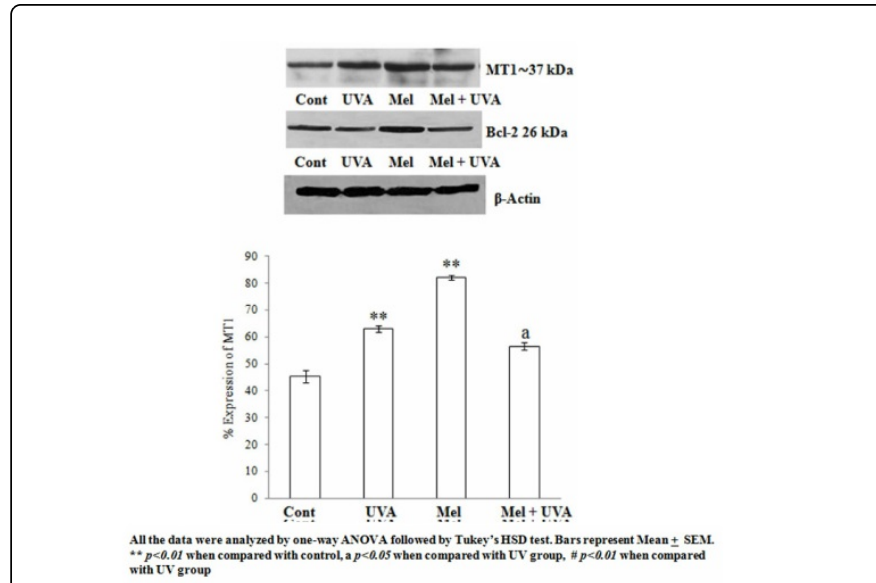

Figure 6: Effect of melatonin pre-treatment $(100 \mu \mathrm{g} / 100 \mathrm{~g}$ b. wt.) on MT1 receptor expression in the skin of Funambulus pennanti following in vivo exposure of $6.36 \mathrm{~J} / \mathrm{cm}^{2} \mathrm{UVA}$ radiation.

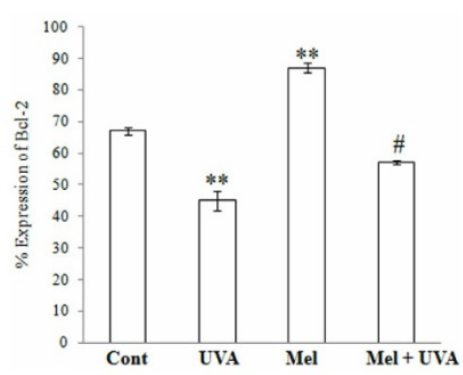

All the data were analyzed by one-way ANOVA followed by Tukey's HSD test. Bars represent Mean \pm SEM. ${ }^{* *} p<0.01$ when compared with control, a $p<0.05$ when compared with $\mathrm{UV}$ group, $\# p<0.01$ when compared with UV group

Figure 7: Effect of melatonin pre-treatment $(100 \mu \mathrm{g} / 100 \mathrm{~g}$ b. wt.) on Bcl-2 expression in the skin of Funambulus pennanti following in vivo exposure of $6.36 \mathrm{~J} / \mathrm{cm}^{2}$ UVA radiation.

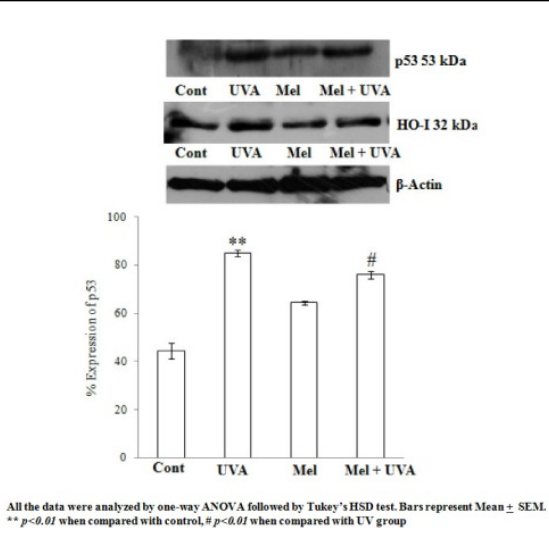

Figure 8: Effect of melatonin pre-treatment $(100 \mu \mathrm{g} / 100 \mathrm{~g} \mathrm{~b}$. wt.) on p53 expression in the skin of Funambulus pennanti following in vivo exposure of $6.36 \mathrm{~J} / \mathrm{cm}^{2} \mathrm{UVA}$ radiation. 


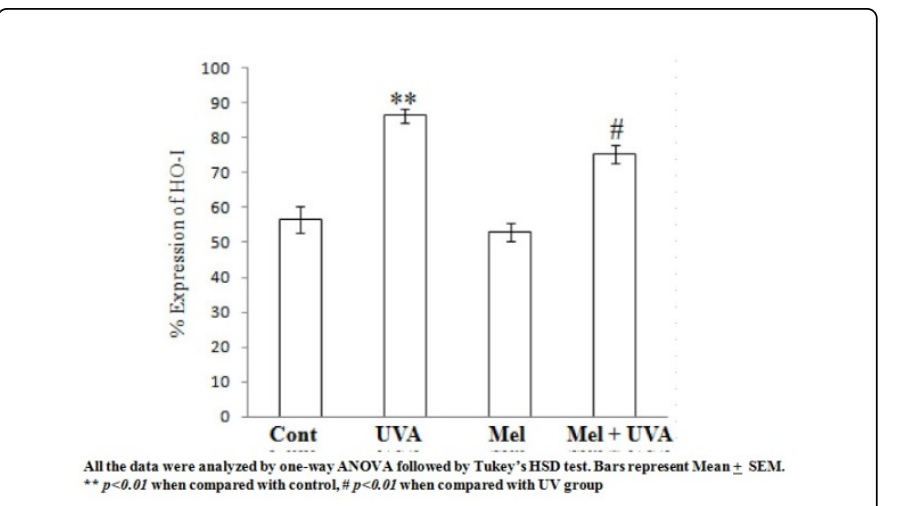

Figure 9: Effect of melatonin pre-treatment ( $100 \mu \mathrm{g} / 100 \mathrm{~g}$ b. wt.) on HO-I expression in the skin of Funambulus pennanti following in vivo exposure of $6.36 \mathrm{~J} / \mathrm{cm} 2$ UVA radiation.

\section{Discussion}

The UVA radiation of $6.36 \mathrm{~J} \mathrm{~cm}^{-2}$ incurred serious oxidative damages to the skin of the tropical rodent $F$. pennanti as depicted by the high levels of TBARS denoting the loss of membrane integrity due to the acute loss of the lipids. UVA radiation is a potent pro-oxidant factor [23] that is present in the sun rays that reaches the earth and this secondary physiological anomaly readily leads to skin carcinomas. There are instances of 1 in 60 Americans developing fatal melanomas [24] and the frequency is alarming indeed. The severity of UVA is partly due to the fact that there are very few known substances that are proved to be effective against UVA because the majority of the commercial sunscreens block UVB and not UVA [25]. However, it was well demonstrated by our study that when UVA is delivered at a proper dose, it can be deleterious.

The suppressed activities of the antioxidant enzymes following UVA radiation further deteriorated the conditions of the tissue milieu and as a result the rate of lipid peroxidation increased that led to the destruction of cell membranes. The pre-treatment of melatonin in vivo as a protective factor has never been investigated before in case of any tropical rodents and it certainly proved effective in alleviating the UVA induced oxidative damages. The loss of cellular integrity might also be the cause for the depletion of the activity of the AANAT in the skin which is the rate limiting enzyme for melatonin biosynthesis.

Thus, the loss of the local melatonergic circuit further aided the oxidative damages due to the loss of the potent antioxidant, local melatonin. Melatonin is primarily synthesized from the pineal gland [26] but in the recent past it has also been shown that the skin contains the entire melatonin synthesizing machinery [27]. Among the wide plethora of physiological functions that melatonin governs, the antioxidant capacity is the property best suited for the skin milieu which is always at the exposure to various kinds of biotic and abiotic stress. This antioxidative attribute of melatonin is hypothesized as the most primitive function of the hormone that has evolved even from the eukaryotes to the present day animals and plants [28]. The beneficial effects of melatonin also comes from its role as a potent stimulator of the gene expression of the enzymatic antioxidant defences primarily SOD and GSH-Px, thereby augmenting the activities of the enzymes [29] as also observed in the present experiment. The melatonin pre-treatment helped to recover the activities of the SOD and GSH-Px, the two most important enzymes for the dismutation of superoxide $\left(\mathrm{O}_{2}^{-}\right)$and $\mathrm{H}_{2} \mathrm{O}_{2}$. The active scavenging of the free radicals is a property exhibited by melatonin [30] due to its high lipophilicity as it enters inside the cell milieu and scavenges the free radicals. Thus, the scavenging of the free radicals and the increase in the activities of SOD and GSH-Px by melatonin could have led to the decrease in the free radical content, thereby declining the lipid peroxidation. The restoration of the redox balance due to the melatonin pre-treatment also aided in the recovery of the skin AANAT activity that was possibly affected by the intense oxidative load and the local melatonergic system showed significant restoration upon melatonin pre-treatment (before the UVA radiation).

The oxidative stress incurred upon the cutaneous tissue led to apoptosis that was confirmed by the suppressed expression of $\mathrm{Bcl}-2$ and up regulated expression of p53. Due to its anti-apoptotic properties melatonin actively up regulated the $\mathrm{Bcl}-2$ levels and suppressed the over expressed p53 transcription factor, thus protecting the skin tissue from the apoptosis induced by the oxidative stress. Heme oxygenase I (HO-I) is another very sensitive and reliable cellular marker for oxidative stress [31]. Although low levels of HO-I is beneficial against oxidative stress [32] yet, expression of HO-I at excessively higher levels are cytotoxic [33]. HO-I has also been linked to apoptosis induction and progression in myocardial pathology [34]. We found significantly higher expression of HO-I upon UVA irradiation which is a primary identification of the oxidative stress. However, the heme degrading capacity of HO-I might also had affected the CAT activity by degrading the enzyme which has a central hememoiety. The free labile iron generated as a result of heme degradation might have aggravated the lipid peroxidation levels by generation of hydroxyl radicals $(\cdot \mathrm{OH})$ by Fenton type of reactions. Melatonin pre-treatment was effective in suppressing the HO-I activity but it was still higher than the control group thus exhibiting a cytoprotective action at the relevant levels only. Therefore, melatonin did not completely suppress the HO-I but prevented the over expression that makes the enzyme cytotoxic. UVR causes an elevation of the MT1 due to photo-oxidative events [35] and our results demonstrated similar expression patterns too. Melatonin when administered exogenously up regulates its MT1 receptor expression in case of this rodent as published by our laboratory in previous studies [36] and we found similar expression pattern of the MT1 receptor. Interestingly, the lowered expression of the MT1 receptor in case of the melatonin pre-treatment was probably due to the inhibition of the photo-oxidative changes by melatonin. However, the receptor expression was higher than the control animals that indicated that the anti-apoptotic action of melatonin might have involved the MT1 to augment the Bcl-2 levels.

Thus, it can be hypothesized from the results that melatonin scavenged the free radicals generated by UVA and alleviated the skin tissue from the harmful free radicals principally by a non-receptor mediated direct mechanism of action. The suppression of the over expressed HO-I further decreased the excess degradation of heme and release of labile iron. The up regulation of the enzymatic antioxidants by melatonin simultaneously protected the skin against the UVA mediated oxidative stress. However, the membrane receptor MT1 might also have been involved in the up regulation of Bcl-2 levels and suppression of stress induced apoptosis. Further studies are needed to conclude the involvement of MT1 more precisely, yet the involvement of the receptor in protection against UVA can very well be proposed. 


\section{Conclusion}

Skin cancers are becoming a serious threat to mankind due to the increased prevalence of UVR on the Earth. The UVA is particularly very deleterious owing to its high concentration in sun rays, oxidizing property and ability to generate free radicals. The geographical location of India makes it an UV prone zone and thus studies concerning UVR mediated damages are very critical. UVA incurred a severe extent of oxidative stress in the skin of the diurnal rodent which led to membrane disintegration due to loss of lipids and eventually culminating in apoptosis.

Melatonin when administered certainly proved effective against the oxidative damages caused by the UVA radiation particularly by the active scavenging of the harmful free radicals. Although primarily acting directly on the free radicals to detoxify them, the action of melatonin might also have involved its membrane receptor MT1 to restore the suppressed Bcl-2 levels for prevention of the stress mediated apoptosis. Thus, melatonin in the form of dermal applications or food supplementations might prove effective to nullify the harmful effects of UVA radiation and decrease the incidences of UV mediated skin malignancies.

\section{Acknowledgement}

The authors report no conflict of interest either financial or personal. Financial help from BRNS- DAE vide research project no. 2010/37B/19/BRNS to Prof. C. Haldar is appreciated. The kind instrument gift from Alexander von Humboldt Foundation, Bonn, Germany is gratefully acknowledged.

\section{References}

1. Slominski A, Wortsman J, Luger T, Paus R, Solomon S (2000) Corticotropin releasing hormone and proopiomelanocortin involvement in the cutaneous response to stress. Physiol Rev 80: 979-1020.

2. Godar DE (2005) UV doses worldwide. Photochem Photobiol 81: 736-749.

3. Doré JF, Chignol MC (2012) Tanning salons and skin cancer. Photochem Photobiol Sci 11: 30-37.

4. D'Orazio J, Jarrett S, Amaro-Ortiz A, Scott T (2013) UV radiation and the skin. Int J Mol Sci 14: 12222-12248.

5. Polefka TG, Meyer TA, Agin PP, Bianchini RJ (2012) Effects of solar radiation on the skin. J Cosmet Dermatol 11: 134-143.

6. Sklar LR, Almutawa F, Lim HW, Hamzavi I (2013) Effects of ultraviolet radiation, visible light, and infrared radiation on erythema and pigmentation: A review. Photochem PhotoBiol Sci 12: 54-64.

7. Jaszewska E, Soin M, Filipek A, Naruszewicz M (2013) UVA-induced ROS generation inhibition by Oenothera paradoxa defatted seeds extract and subsequent cell death in human dermal fibroblasts. J Photochem Photobiol B 126: 42-46.

8. Tyrrell RM (1995) Ultraviolet radiation and free radical damage to skin. Biochem Soc Symp 61: 47-53.

9. Sander CS, Chang H, Hamm F, Elsner P, Thiele JJ (2004) Role of oxidative stress and the antioxidant network in cutaneous carcinogenesis. Int J Dermatol 43: 326-335.

10. Maverakis E, Miyamura Y, Bowen MP, Correa G, Ono Y, et al. (2010) Light, including ultraviolet. J Autoimmun 34: J247-J257.

11. Tang HMV, Siu KL, Wong CM, Jin DY (2009) Loss of yeast peroxiredoxin Tsalp induces genome instability through activation of the DNA damage checkpoint and elevation of dNTP levels. PLoS Genet 5: e1000697.

12. Cerbone A, Toaldo C, Laurora S, Briatore F, Pizzimenti S, et al. (2007) 4Hydroxynonenal and PPAR? ligands affect proliferation, differentiation, and apoptosis in colon cancer cells. Free Radical Biol Med 42: 1661-1670.
13. Ou-Yang H, Stamatas G, Saliou C, Kollias N (2004) A chemiluminescence study of UVA-induced oxidative stress in human skin in vivo. J Invest Dermatol 122: 1020-1029.

14. Emonet-Piccardi N, Richard MJ, Ravanat JL, Signorini N, Cadet J, et al. (1998) Protective effects of antioxidants against UVA-induced DNA damage in human skin fibroblasts in culture. Free Radic Res 29: 307-313.

15. Hussein MR, Haemel AK, Sudilovsky O, Wood GS (2005) Genomic instability in radial growth phase melanoma cell lines after ultraviolet irradiation. J Clin Pathol 58: 389-396.

16. Bishnupuri KS, Haldar C (2001) Maternal Transfer of melatonin alters the growth and sexual maturation of young Indian palm squirrel, Funambulus pennanti. Biol Signals Recept 10: 317-325.

17. Ohkawa H, Ohishi N, Yagi K (1978) Reaction of linoleic acid hydroperoxide with thiobarbituric acid. J Lipid Res 19: 1053-1057.

18. Das K, Samanta L, Chainy NBC (1999) A modified spectrophotometric assay of superoxide dismutase using nitrite formation by superoxide radicals. J Biochem Biophysiol 37: 201-204.

19. Sinha AK (1972) Colorimetric assay of catalase. Anal Biochem 47: 389-394.

20. Mantha SV, Prasad M, Kalra J, Prasad K (1993) Antioxidant enzymes in hypercholesterolemia and effects of vitamin $\mathrm{E}$ in rabbits. Atherosclerosis 101: 135-144.

21. Chae HD, Park TJ, Lee YK, Lee TG, Kim KT (1999) Rapid and simple measurement of serotonin $\mathrm{N}$-acetyl transferase activity by liquid biphasic diffusion assay. Neurochem Int 35: 447-451.

22. Goswami S, Haldar C (2014) Melatonin improves UVB induced oxidative damages and inflammatory conditions of cutaneous tissue of a diurnal Indian palm squirrel Funambulus pennanti. Br J Dermatol 17: 1147-1155.

23. Burke KE (2010) Photoaging: the role of oxidative stress. G Ital Dermatol Venereol 145: 445-459.

24. Croyle RT SEER Stat Fact Sheets: Melanoma of the Skin.

25. Sage E, Girard PM, Francesconi S (2012) Unravelling UVA-induced mutagenesis. Photochem Photobiol Sci 11: 74-80.

26. Lerner AB, Case JD, Takahashi Y, Lee TH, Mori W (1958) Isolation of melatonin, a pineal factor that lightens melanocytes. J Am Chem Soc 80: 2057-2058.

27. Slominski A, Pisarchik A, Semak I, Sweatman T, Wortsman J, et al. (2002) Serotoninergic and melatoninergic systems are fully expressed in human skin. FASEB J 16: 896-898.

28. Tan DX, Manchester LC, Liu X, Rosales-Corral SA, Acuna-Castroviejo D, et al. (2013) Mitochondria and chloroplasts as the original sites of melatonin synthesis: a hypothesis related to melatonin's primary function and evolution in eukaryotes. J Pin Res. 54: 127-138.

29. Tomás-Zapico C, Coto-Montes A (2005) A proposed mechanism to explain the stimulatory effect of melatonin on antioxidative enzymes. J Pineal Res 39: 99-104.

30. Galano A, Tan DX, Reiter RJ (2013) On the free radical scavenging activities of melatonin's metabolites, AFMK and AMK. J Pineal Res 54: 245-257.

31. Maines MD (1997) The heme oxygenase system: a regulator of second messenger gases. Annu Rev Pharmacol Toxicol 37: 517-554.

32. Dennery PA, Wong HE, Sridhar KJ, Rodgers PA, Sim JE, et al. (1996) Differences in basal and hyperoxia-associated HO expression in oxidantresistant hamster fibroblast. Am J Physiol 27: L672-L679.

33. Suttner DM, Dennery PA (1999) Reversal of HO-1 related cytoprotection with increased expression is due to reactive iron. FASEB J 13: 1800-1809.

34. Ursu ON, Sauter M, Ettischer N, Kandolf R, Klingel K (2014) Heme oxygenase-1 mediates oxidative stress and apoptosis in coxsackievirus B3-induced myocarditis. Cell Physiol Biochem 33: 52-66.

35. Slominski A, Fischer TW, Zmijewski MA, Wortsman J, Semak I, et al. (2005) On the role of melatonin in skin physiology and pathology. Endocrine 27: 137-148.

36. Ahmad R, Haldar C (2010) Effect of intra-testicular melatonin injection on testicular functions, local and general immunity of a tropical rodent Funambulus pennanti. Endocr 37: 479-488. 